A AUTORA

Maria Aparecida Baccega

Professora Livre-Docente do Departamento de

Comunicações e Artes da ECA-USP. Coordenadora do

curso de Pós-Graduação lato sensu Gestão de

Processos Comunicacionais.

\title{
TECNOLOGIA E CONSTRUÇÃO DA CIDADANIA
}

A

$\mathrm{s}$ tecnologias servem para ampliar a comunicação primeira, aquela que se dá através do aparelho fonador, utilizando-se fundamentalmente da linguagem: código verbal (língua) e não verbais (os gestos, por exemplo). Podemos ilustrar com uma conversa a dois. Ela ocorrerá sem maiores transtornos. Se, porém, ao invés de atingirmos apenas o nosso interlocutor, quisermos atingir um auditório, provavelmente usaremos microfone. Se, mais que um auditório, quisermos atingir pessoas em lugares mais distantes e em número maior - já na casa dos milhares e até milhões - podemos optar pelo rádio. Se a imagem for indispensável, aí entra a televisão. E se quisermos interagir com o interlocutor em tempo real, podemos usar a Internet.

Percebemos, por esse exemplo, que, na verdade, as tecnologias nada mais fazem que amplificar o que queremos dar a conhecer, cujo conteúdo avaliamos como importante. Se quisermos controlar, ampliaremos o controle (vide a expansão da ideologia nazista que tanto se utilizou do rádio). Não podemos nos esquecer de que a televisão também é uma grande conquista tecnológica e, pelo que se ouve predominantemente, ela não vem sendo utilizada da maneira mais adequada à formação cidadã. Já se temos um projeto pedagógico que atende às exigências de diálogo, de interação, de respeito a todos os envolvidos, as tecnologias servirão para sua divulgação e operacionalização, atingindo maior número de participantes.

\section{TECNOLOGIA E ENSINO}

Com isso pretendemos tornar claro que consideramos um equívoco - que vem se tornando frequiente - a concepção segundo a qual o uso das tecnologias, sobretudo as 
chamadas novas (rádio e televisão) e novíssimas, como a TV a cabo ou a Internet, caracterizam por si só um ensino de qualidade. $\mathrm{O}$ ensino de qualidade continua a ser aquele que busca, através de projetos adequados, a inserção do aluno como cidadão crítico. O uso da tecnologia poderá favorecê-lo, ampliá-lo, mas sua ausência não implicará falta de qualidade. Ao contrário, o uso da tecnologia em projetos inadequados, muitas vezes pensados apenas como vitrina de modernidade, falsa, têm-se revelado prejudiciais ao processo de educação. É bom lembrar recente publicidade na qual um aluno de ensino fundamental lê uma pesquisa que fez pela Internet e que pára repentinamente, por problema técnico em seu computador, em "Os mamíferos são...". Entra o nome do produto e na sequência o mesmo aluno volta com um número imenso de páginas impressas, que são os mamíferos encontrados na Internet. Notamos, explicitamente, que o conceito de pesquisa passou a ser o de impressão pura e simples, sem qualquer seleção, daquilo que a Internet traz e que, como sabemos, se tem muita coisa boa, tem também muito lixo. E aí reside seu caráter democrático, o que aumenta a responsabilidade da escola na formação do receptor crítico, capaz de selecionar.

Não estamos colocando em dúvida a necessidade do uso adequado das tecnologias. Apenas chamamos a atenção para seu indevido endeusamento, o que coloca, mais uma vez, a necessidade da formação de profissionais no campo da comunicação/educação, quer sejam advindos do campo da educação, quer sejam advindos do campo da comunicação, pois, na verdade, trata-se de um profissional que se caracteriza pela transdisciplinaridade e que poderá dar conta da formação desse cidadão imerso no ecossistema comunicativo da contemporaneidade.

\section{TECNOLOGIA E FORMAÇÃO HUMANÍSTICA}

"O desenvolvimento da capacidade de pensamento deveria ser colocado em primeiro lugar, e não a aquisição de conhecimento especializado. Se uma pessoa domina o fundamental no seu campo de estudo e aprendeu a pensar independentemente, ela será mais capaz de adaptar-se ao progresso e às mudanças do que outra cujo treinamento consistiu apenas na aquisição de conhecimento detalhado"' . Eis aí, na fala de um cientista acima de qualquer suspeita quanto à criatividade, o papel primeiro da escola em geral e, em particular, do uso da tecnologia na educação.

Outro aspecto que não podemos esquecer é que nossos alunos nasceram e estão se constituindo enquanto cidadãos nessa nova realidade, que alguns chamam de sociedade da informação, sociedade do conhecimento ou infoera. Nessa nova realidade, os valores de compartilhamento, de interação, o relacionamento humano estão se modificando velozmente. Recebemos um excesso de informação, em escala muito maior do que podemos absorver. E, nessa escalada estonteante, a informação acaba passando por conhecimento, deixando em todos as marcas da fragmentação, que são o caminho para o insucesso na busca de mudanças sociais que beneficiem a todos, que incluam os 
milhões que se encontram fora das conquistas da humanidade, muitas vezes até sem ter o que comer. Só o conhecimento, com sua percepção de totalidade, pode ajudar na seleção do que é efetivamente importante e necessário para as mudanças históricas ${ }^{2}$.

Segundo João Antônio Zuffo, essa nova realidade traz consequiências no campo do ensino. O curso superior, diz o professor ${ }^{3}$, deverá ter uma base sólida na área de humanidades e artes, fazendo com que o aluno seja capaz de lidar com as constantes mudanças e tenha formação suficiente para saber o que quer, onde encontrar e como selecionar aquilo de que precisa. Quanto ao conhecimento especializado, este seria fornecido por cursos just in time, rápidos, em geral on line, sob a responsabilidade de um orientador. Trata-se de informações que logo se tornarão obsoletas, pois a celeridade das mudanças tecnológicas já é hoje uma constatação. Desse modo, percebemos que a educação continuada deixa de ser uma expressão vazia de significado para se tornar efetiva. E mais: só poderá obter êxito os que forem capazes de pensar. E aí voltamos para a citação de Einstein.

Já o ensino fundamental sofrerá modificações ainda maiores, segundo o mesmo professor. Os cursos deverão se voltar para a criatividade e para os aspectos vocacionais das crianças. $\mathrm{O}$ ensino terá que ser personalizado e ministrado de acordo com a capacidade e competência de cada um. Haverá profunda mudança na filosofia de ensino, pois as crianças aprenderão as disciplinas de forma atrativa.

Como podemos perceber, o avanço da tecnologia faz com que sejam retomados os aspectos humanísticos, a formação geral que, por equívoco, foram colocados de lado com o advento dessas tecnologias.

\section{TECNOLOGIA, INFORMAÇÃO E CONHECIMENTO}

Outro aspecto a ser considerado é o fato de que se usa a tecnologia, muitas vezes, para fazer de outro modo o mesmo, aquilo que se fazia antes, com os mesmos princípios. A tecnologia serve simplesmente para acelerar, fazer mais depressa. Ou seja, faz-se o uso de uma nova tecnologia de maneira antiga. (Usa-se o computador como se fosse uma máquina de escrever.) Por isso, como dissemos, ela tem servido simplesmente para amplificar o já visto, o já dito e não para introduzir reflexões novas, sobretudo no que se refere ao processo ensino-aprendizagem.

Por outro lado, é inegável que à tecnologia se reserva um papel altamente positivo: ele se refere à possibilidade, que é da natureza dela, de constituir-se na base de um processo de construção coletiva de conhecimentos, que tem sido divulgado como conhecimento em rede.

O caráter complexo da realidade contemporânea exclui a possibilidade de indivíduos com saberes suficientes para dar conta do que acontece no dia-a-dia. A concepção de chefes que ditam as normas, ainda que eles sejam dotados de uma super-inteli-

2. BACCEGA, Maria Aparecida. Conhecimento, informação e tecnologia. Comunicação \& Educação. São Paulo: CCA-ECA-USP/Moderna, n.11, jan./abr. de 1998. p. 7-16.

3. ZUFFO, João Antônio. O ensino da nova era ... op. cit. 
gência, ou de professores que, sozinhos, são capazes de enfrentar os problemas que se renovam constantemente não tem mais sentido. Hoje, faz-se necessário que o conhecimento seja uma construção coletiva, que, ainda que se dê a partir de entradas específicas (e aqui estamos pensando nos campos de conhecimento instituídos, como a Linguagem, a Sociologia, a História, a Filosofia etc.), certamente necessita da colaboração dos outros campos de conhecimento, os quais se metassignificam nesse diálogo inter-campos. Como vemos, elites de pensadores, chefes totalitários, professores que trabalham isoladamente não mais se justificam. Se é verdade que tal diálogo, tal interação pode se dar através de instituições, de reuniões, também fica evidente que a presença da Internet estimulará esse intercâmbio, esse compartilhamento. Daí seu caráter democrático, pelo qual devemos lutar.

Nessa profusão de saberes, selecionar o que convém passa a ser a necessidade maior. Hoje, já é possível ao leitor selecionar o que quer ler (que editoria ele considera indispensável) na imprensa on line. E, muitas vezes, até interferir no conteúdo da notícia. Mas, se ele não frequienta as outras editorias, como sabe que não precisa conhecê-las? ${ }^{4}$

Como diz Michel Authier, "crer na democracia é crer que cada cidadão seja capaz de escolher o que é melhor para si"'s. E, para que nos tornemos cidadãos, haveremos que levar em conta que "informação não equivale a conhecimento. Informação necessita de estruturas conceptuais que a suportem e lhe dêem sentido. Ainda que possa parecer estranho, a informação também gera ignorância e desconcerto na ausência de marcos teóricos, conceptuais e axiológicos que lhe dêem sentido"6.

\section{TECNOLOGIA E INCLUSÃO DIGITAL}

Em termos de Brasil sabemos que ainda é muito pequeno (com relação à totalidade da nossa população) o número daqueles que têm acesso à Internet. Segundo Icoletiva? baseando-se no Ibope eRatings, o número de usuários domiciliares da Internet no Brasil cresceu em janeiro de 2003, chegando a 7,5 milhões de pessoas. O número de horas navegadas também cresceu, atingindo 11 horas e 10 minutos por mês. Os sites mais procurados incluem os de Carreiras e Empregos, com 18,8\% dos usuários ativos. Desse total, $40 \%$ têm nível superior ou pós-graduação, o que pode ajudar a esclarecer a questão da inclusão digital. Onde ela se localiza? Tal pista se completa com outro dado: foram 3,2 milhões os que procuraram sites de Notícias e Informações, todos usuários pertencentes às classes $\mathrm{A}$ e $\mathrm{B}$, segundo o Ibope.

4. Ver MACHADO, Arlindo. As comunicaşões sob o impacto da informática. Comunicação \& Educação. São Paulo: CCA-ECA-USP/Moderna, n. 2, jan./abr. de 1995. p.14-20.

5. AUTHIER, Michel. A construção coletiva dos conhecimentos.

http://www.icoletiva. com.br/seção.asp?tipo=entrevistas\&id=4. Acessado em fevereiro de 2003.

6. NUÑEZ JOVER, Jorge. La ciencia y la tecnologia como procesos sociales. Lo que la educación científica no debería olvidar. (A ciência e a tecnologia. O que a educação científica não deveria esquecer.) La Habana: Editorial Félix Varela, 1999.

7. http://www.icoletiva.com.br/secao.asp?tipo=editorial Acessado em fevereiro de 2003. 
Num país que tem hoje cerca de 170 milhões de habitantes, 42 milhões de domicílios com TV aberta, 3,5 milhões de assinantes de TV por assinatura e 7,5 milhões de usuários de Internet, sendo que muitos dos que aparecem nas TVs por assinatura são certamente os mesmos que se utilizam da Internet, podemos afirmar que falta muito para a inclusão digital, tão necessária na sociedade contemporânea. ${ }^{8}$

Na busca dessa inclusão social e digital, a Escola desempenha importante papel, já que é o lugar privilegiado da socialização, dos encontros marcados para reflexão, para construção de cidadania. E no bojo desse papel de que a Escola não pode - e não quer - se furtar, está a comunicação/educação. Ensinar a ler os meios, possibilitar conhecimento para que a seleção seja adequada aos interesses coletivos constituem a base do que vem sendo chamado de $5^{\circ}$ poder: o poder da sociedade nas suas relações com a mídia.

Ajudar a desvelar as mídias, perceber o que existe no processo de sua elaboração, saber o modo que é editado o mundo que nos é dado a conhecer têm sido objetivos da revista Comunicação \& Educação, a qual neste número trata de jornal, televisão, cinema, educação a distância, material educativo, gestão de comunicação, entre outros temas importantes para o campo.

\section{ARTIGOS NACIONAIS}

Conhecimento e informação. Essa dualidade, que aparece flagrantemente na mídia em geral, é particularmente presente no jornalismo. A partir de Paulo Freire, pensador que tanto colabora com as reflexões dos que trabalham com educação, Eduardo Meditsch propõe que se pense o jornalismo enquanto conhecimento, objetivando o avanço na compreensão dos condicionamentos das práticas cognitivas inerentes à atividade jornalística, tanto no pólo da produção quanto no da recepção. É o que se pode ver em Filosofia de Paulo Freire e práticas cognitivas no jornalismo. "Nas últimas décadas se multiplicaram os trabalhos científicos que salientam o fato de o Jornalismo não ser uma imagem da realidade extraída unicamente desta realidade, mas sim uma construção onde os projetos, as técnicas e seu manejo, as ferramentas e as matérias-primas também interferem no produto final". Destaquem-se as técnicas narrativas e a espetacularização, as quais "se justificam amplamente pela eficácia comunicativa e cognitiva que proporcionam. O problema é quando passam a ser utilizadas em função de objetivos que não os cognitivos, como a luta comercial por audiência e o esforço político de persuasão".

Ética e cinema: notas sobre uma experiência didática, de Rogério Christofoletti, mostra como "a relação do homem com o conhecimento foi totalmente alterada com a intervenção dos meios de comunicação de massa. O desenvolvimento das tecnologias de impressão, a difusão massiva das idéias em meios eletrônicos e a mais recente digitalização dos dados acarretam profundas modificações no cotidiano mais prosaico dos seres humanos". A partir dessa constatação, que pode fazer o professor para adequar-se a essa

8. Ver MORÁN, José Manuel. Internet no ensino. Comunicação \& Educação. São Paulo: CCA-ECA-USP/Moderna, n. 14, jan Jabr. de 1999. p. 17-26. 
nova sensibilidade de seus alunos, objetivando a discussão e a reflexão sobre conteúdos a serem ministrados? O artigo relata uma experiência que deu certo, no estudo de ética e jornalismo, com o uso de filme em vídeo, "enquanto elemento de revisão dos tópicos, catalisador das discussões e ilustrativo de temas mais complexos", indo "muito além da apresentação expositiva dos tópicos em aula, fomentando o debate a partir das cenas dos filmes e aprofundando as questões com os alunos". Não podemos deixar de registrar que esta tem sido uma preocupação constante de nossa revista, expressa na seção Videografia, escrita por Maria Ignês Carlos Magno.

Bernard Charlot escreve sobre escola. É autor conhecido, que tem se mostrado importante nas discussões atuais. Neste artigo, Cláudio Magalhães parte dessa contribuição para aplicá-la à realidade da televisão, no artigo $A$ inter-relação entre criança $e$ TV. Entre as três justificativas para essa aproximação, uma se destaca: é que "a escola não é lá tão diferente assim da TV" - são poucos transmitindo, de modo tradicional, informação para muitos; "os alunos/assistentes em grande parte colocados em um papel passivo diante do professor/TV; muitas críticas e poucas mudanças, com professores e programadores de TV resistentes às mudanças". Assim como Charlot, Cláudio Magalhães pensa "a influência como uma relação" e não como caminho de mão única, em que o receptor é apenas objeto.

\section{ARTIGO INTERNACIONAL}

Gabriel Kaplún colabora neste número com o artigo Material educativo: a experiência de aprendizado. Nele, o autor discute a construção e análise de materiais educativos, fazendo o laço teórico-prático implicado em três eixos: conceitual, pedagógico e comunicacional. Segundo o autor, a "aventura da criação" de um material educativo começa sempre pela pesquisa do estado da arte sobre o tema. Daí serão retirados os aspectos mais importantes de acordo com os objetivos determinados e com o público a que se destina. Já "o eixo pedagógico é, ou deveria ser, segundo nos parece, o articulador principal de um material educativo, se é que queremos que ele seja realmente educativo. É através dele que estabeleceremos um ponto de partida e um ponto de chegada, em termos de tentativa, para o destinatário do material. Ou seja, é assim que lhe propomos um caminho, que ele é convidado a percorrer, uma nova perspectiva que queremos abrir para ele ou que the propomos que descubra". O modo concreto de percorrer esse caminho "ou, quem sabe, o veículo no qual o percorreremos" constitui o eixo comunicacional. "Elaborar um material não é apenas transmitir um conhecimento já existente, mas sim, em certa medida, produzir o novo."

\section{ENTREVISTA}

O entrevistado deste número é Gabriel Priolli. Em Receptores mais críticos, TV de melhor qualidade, trabalho realizado por Roseli Fígaro, ele fala de sua formação e de sua extensa experiência profissional, do papel do crítico de TV e da importância da crítica, da formação de jovens jornalistas, em que ele destaca duas coisas como absolutamente importantes: "o estudo da língua e de História". Sobre a formação das novas 
gerações, lembra que "o volume da informação hoje é muito grande, mas a qualidade dessa informação é discutível". A leitura de livros é indispensável. "Ao não ler livros, perde-se um determinado tipo de informação. Não que ela não esteja disponível na Internet, mas a forma que se aprende na Internet é muito mais fragmentada do que aquela que se lê no próprio livro."

Ele fala ainda sobre as poucas empresas de comunicação que controlam todo o processo cultural, sobre a qualidade da programação, sobre televisão educativa e sobre o papel da escola nessa realidade, entre outros temas.

\section{CRÍTICA}

A crítica deste número vem no texto de Maria Cristina Castilho Costa e trata de Educação a distância - entre o entusiasmo e a crítica. A autora participou da Conferência Anual da Associação de Centros de Ciência e Tecnologia, nos Estados Unidos, e vivenciou, na condição de participante de um workshop, uma teleconferência sobre História Natural. É essa experiência que ela nos conta, inserindo suas observações na discussão sobre educação a distância.

\section{DEPOIMENTO}

Especialista em Gestão de Processos Comunicacionais pela Escola de Comunicações e Artes, Ana Luisa Zaniboni Gomes, que trabalha na Oboré e é reponsável pelo Núcleo de Rádio, traz seu depoimento sobre o papel do gestor em projeto que envolve o rádio e seus subprodutos. Unindo pontas soltas é o sugestivo título do texto. Discute qual "o papel real de um Núcleo que cria, produz e distribui programas especiais de rádio para emissoras cidadãs - comerciais e comunitárias - reunidas em redes temáticas de parceria e cooperação". Um dos grandes desafios operacionais, lembra a autora, "é como garantir, num país tão grande e diverso como o Brasil, uma linguagem que respeite as diferenças regionais e que seja popular e compreensível para a maioria das pessoas".

\section{EXPERIÊNCIA}

O jornalismo como fonte de ensino é o título do texto que nos traz o projeto Fazer, gostar e aprender: uma produção de jornal, desenvolvido por Tânia Regina Gonçalves Figueiredo, com alunos do Ensino Fundamental na Escola Estadual de Ensino Fundamental Antônio Gomes de Oliveira, em Marília, São Paulo. Trata-se de projeto interdisciplinar, que cuida da produção dos diferentes tipos de texto e cujo êxito se pode avaliar pela participação de todos os alunos, inclusive daqueles com defasagem na aprendizagem.

\section{POESIA}

Renata Pallottini nos leva ao mundo da poesia Vallegrande mostra como a natureza, a vida e a morte se entrelaçam compondo um caminho de indistintas moradas. 


\section{SERVIÇOS}

Vila Brasileira: um programa para protagonistas juvenis, de Sérgio Perales, tem por objetivo capacitar jovens com a finalidade de torná-los empreendedores e multiplicadores culturais, como um dos possíveis caminhos de combate à exclusão social e à violência urbana. Para tanto, utiliza-se da cultura e do espaço urbano como modo de transformação social do indivíduo e da sua comunidade.

\section{VIDEOGRAFIA}

$O$ desenho animado em sala de aula é o tema de que trata Maria Ignês Carlos Magno, neste número. Discussão sempre presente no âmbito da educação formal e não formal, os efeitos da TV, em geral considerados maléficos, têm nos desenhos animados um de seus alicerces. Segundo a autora, sua preocupação foi com o professor de Ensino Fundamental I, sempre tão exigido e nem sempre lembrado. São seis desenhos selecionados e comentados.

\section{BOLETIM BIBLIOGRÁFICO}

Bibliografia sobre telenovela brasileira traz teses e dissertações sobre a temática. Bibliografia sobre comunicação e educação traz livros, artigos, relatórios de pesquisa que muito contribuem com a discussão do campo. Endereços úteis na Internet apresenta um elenco de endereços que certamente colaborarão com as tarefas dos professores.

\section{ATIVIDADES EM SALA DE AULA}

Ruth Ribas Itacarambi propõe projetos pedagógicos a serem desenvolvidos em sala de aula com alunos de Ensino Fundamental e Médio, utilizando-se dos artigos publicados neste número.

Resumo: $\mathrm{O}$ artigo discute a função das novas tecnologias na construção da cidadania. Mostra que elas não caracterizam por si só um ensino de qualidade, que para isso é preciso projetos adequados para a inserção do aluno como cidadão crítico. Nesse sentido as novas tecnologias vêm para favorecer e ampliar o ensino de qualidade. A autora também mostra que hoje faz-se necessário que o conhecimento seja uma construção coletiva e para isso a tecnologia tem contribuido muito para o crescimento em rede, o intercâmbio e o compartilhamento de idéias e informações.

Palavras-chave: novas tecnologias, cidadania, ensino de qualidade, conhecimento, informação
(Technology and building citizenship)

Abstract: The article discusses the function of the new technologies in building citizenship. It shows that in and of themselves they do not characterize quality teaching and that for this to be achieved it is necessary to have projects that are adequate to lead the student to be a critical citizen. In this regard, these new technologies favor and enhance teaching quality. The author also shows that these days knowledge must be a collective construction and that technology has contributed very much for the growth of networks, for exchanging and sharing ideas and information.

Key words: new technologies, citizenship, quality teaching, knowledge, information 